\section{Commentary: Modern analytics: Good for surgery, bad for baseball}

\author{
Jacob A. Klapper, MD, FACS
}

In 1990 George F. Will published Men at Work, ${ }^{1}$ a book that chronicled his experience following various baseball stars of the time and most notably the manager Tony LaRussa. Will's examination of LaRussa's approach to the craft of baseball made him out to be a sort of unparalleled genius; Bobby Fischer with cleats, if you will. About 15 years later, Michael Lewis published Moneyball which, in comparison to Will's book, de-emphasized certain conventional (and exciting) aspects of baseball and emphasized some of the more mundane elements (ie, on-base percentage) all in an attempt to make the game more predictable. Thus was born the era of analytics in sports.

Overall, I would say that analytics have made baseball largely unwatchable, as you no longer get to see a runner set up a pitcher for a stolen base or a hitter attempt to "hit behind" the runner on second in a classic hit-and-run play. I've lost interest. In comparison, I read with real interest Chudgar and colleagues' ${ }^{2}$ description of their institution's assessment of the utility of the ACS's Surgical Risk Calculator when analyzing outcomes following lung resections. The Memorial Sloan Kettering Cancer Center group did better than predicted when it came to their observed rates of any complication, any serious complication, and 30day mortality. The authors also found that, for the most part, this general surgical calculator did very well in predicting the complication rates for the various reported outcomes of interest.

From my personal experience with using this risk calculator for the operations that I perform, I have found it to be a useful tool for starting a conversation. I usually fill it out in the examination room with patients I have deemed high

\footnotetext{
From the Division of Cardiothoracic Surgery, Duke University Medical Center, Durham, NC

Disclosures: The author reported no conflicts of interest.

The Journal policy requires editors and reviewers to disclose conflicts of interest and to decline handling or reviewing manuscripts for which they may have a conflict of interest. The editors and reviewers of this article have no conflicts of interest.

Received for publication Jan 21, 2021; revisions received Jan 21, 2021; accepted for publication Jan 22, 2021; available ahead of print Jan 30, 2021.

Address for reprints: Jacob A. Klapper, MD, FACS, Division of Cardiothoracic Surgery, DUMC 3954, Durham, NC 27710 (E-mail: Jacob.klapper@ duke.edu).

J Thorac Cardiovasc Surg 2022;163:1517 0022-5223/\$0.00

Published by Elsevier Inc. on behalf of The American Association for Thoracic Surgery

https://doi.org/10.1016/j.jtcvs.2021.01.084
}

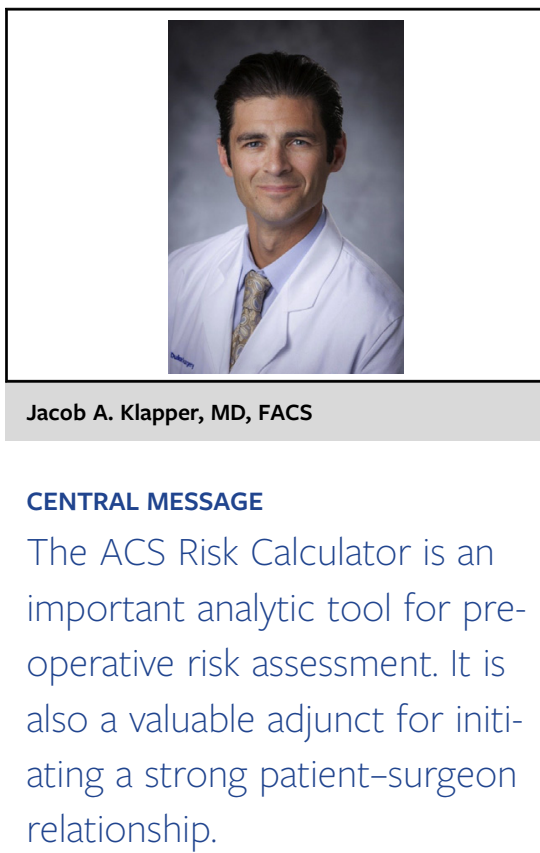

risk. For many, I think, the risk percentages are secondary to the discussion that comes after it, particularly when analyzing their chances of placement in a nursing home after discharge. In essence, I feel that the calculator brings me closer to truly providing informed consent, and I sense that when the critical decision is made to proceed with surgery my patient and I have a shared understanding of what might happen. This reality is a powerful, and I'm not sure, fully intended consequence of the tool, but may, in the end, be just as valuable as the statistical estimates it provides.

In the end, it comes as no surprise that this surgical group performed better than predicted. It also comes as no surprise that the model itself is not perfect. Just as in the application of analytics to sports, there are unpredictable human elements that no one can anticipate. These factors are what still makes sports so exciting. In surgery, unanticipated outcomes are not as exciting, as they are tragic and demoralizing, thus the need for a predictive model, because, as the authors so astutely note, "the preoperative identification and anticipation of perioperative risks is intrinsic to reducing morbidity and mortality." Analytics and risk models bring us closer to obtaining this commendable goal. Now if only they would leave baseball alone.

\section{References}

1. Will GF. Men at Work. New York: Macmillan Publishers; 1990.

2. Chudgar N, Yan S, Hsu M, Tan KS, Gray KD, Molena D, et al. The American College of Surgeons Surgical Risk Calculator performs well for pulmonary resection: a validation study. J Thorac Cardiovasc Surg. 2022;163:1509-16.e1. 